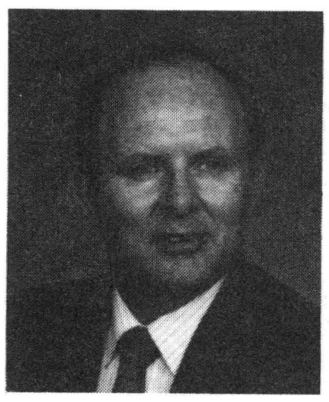

Editorial

Jack D. Gaskill, Editor

\section{A Congressional Attack on} "Fraud" in Science

In the May 15, 1989, issue of The Wall Street Journal, the lead editorial addressed an activity that is taking place in the United States but one that should send chills up the spines of scientists and engineers around the world.

The editorial reports that a U.S. congressman is conducting an investigation into "scientific fraud," ostensibly for the purpose of protecting taxpayers' money and "whistle blowers." It goes on to assert that, in the process, this congressman "and his staff of zealots are harassing scientists at MIT, Duke, Tufts, and the National Institutes of Health, among other places." Furthermore, the editorial contends that this congressional police action will eventually cripple science in the U.S. unless science fights back.

The above information was extracted from just the first two paragraphs of the editorial; in reading the remaining paragraphs I felt as if I had come into possession of an advance copy of Friday the 13th, Part IX. Yes, it was a horror story, but one that I'm afraid does not fall under the category of fiction. I must admit to a prepossession against congressional investigations, a bias you may sense as you read the rest of my editorial.

One of the victims of this investigation, according to The Wall Street Journal editorial, is Dr. David Baltimore, a Nobel laureate and head of MIT's Whitehead Institute. Dr. Baltimore, along with his coauthors of a scientific paper published in 1986, was dragged before public hearings recently to raise "concerns" about their "integrity." Outside scientists had already evaluated the paper three times, "finding technical errors and omissions but no fraud or misconduct." As the editorial went on to point out, "no doubt fraud exists in science, as it does everywhere, but important science is self-correcting. Plagiarists and con men eventually are discovered, which is more than one can say about Congress." A result of this unfortunate witch hunt, as mentioned in a subsequent editorial that appeared in the May 25, 1989, issue of The Wall Street Journal, is that "Dr. Baltimore now spends the bulk of his time not on research or administration, but defending himself against persecution...."

As far as I am concerned, things are bad enough when Congress confines its dabbling to matters in which it is marginally competent; however, the situation becomes much worse when it enters an arena in which it is totally incompetent. What can we expect if Congress decides to make science the target of some federal oversight committee? I'll tell you! In addition to being subjected to the sort of harassment mentioned above, we can expect to be dingellburied under a mountain of mind-boggling regulations and reporting requirements! It can truly be said that the legislative branch of our government has a Midas-like touch, but it is usually not gold into which things turn when touched by Congress.

I find this matter to be so frightening and such a threat to science that, as an individual and not in my capacity as Editor of Optical Engineering, I will make my concerns known to my congresspersons. I should further point out that the views expressed in this editorial are my views and should not be construed to reflect the views of the members, officers, governors, or staff of the Society.

\title{
Future Special Issue Call for Papers
}

June 1990

\section{X-Ray/EUV Optics}

\section{Guest Editor}

Richard B. Hoover

NASA-Marshall Space Flight Center

Space Science Laboratory, ES-52

Huntsville, AL 35812

205/544-7617

The June 1990 special issue of Optical Engineering will be devoted to the subject of x-ray/EUV optics. The intent of this issue is to provide a broad overview of the current state-of-the-art technology of x-ray/EUV optics and instrumentation for astronomy, microscopy, and advanced photon sources. Topics to be covered include x-ray/EUV zone plates, filters, windows, beamsplitters, monochromators, gratings, spectrometers, polarimeters, telescopes, and space observatories and missions. The design, characterization, fabrication, and testing of grazing incidence and multilayer x-ray/EUV optics will be addressed. Grazing incidence optics with applications to free electron lasers, synchrotrons, and other advanced photon sources will be considered. Authors are encouraged to submit manuscripts for consideration on any of the above or related topics to the Guest Editor by November 15, 1989. 